\title{
A study on relationship between cultural intelligence and cross-cultural adjustment in tour management
}

\author{
Mahdi Karroubi, Arghavan Hadinejad* and Seyed Mojtaba Mahmoudzadeh
}

Department of Management and Accounting, Allameh Tabatabaei University, Tehran, Iran

\section{H R O N I C L E}

Article history:

Received December 28, 2013

Received in revised format April

152014

Accepted April 182014

Available online

April 302014

Keywords:

Cultural intelligence

Cross-cultural adjustment

Emotional intelligence

Tour leaders

\begin{abstract}
A B S T R A C T
The purpose of the present study was to examine the effects of cultural intelligence (CQ) and emotional intelligence (EI) on a tour leader's adjustment in a different cultural environment. Data were collected from 330 outgoing tour leaders in Tehran, Iran. The construct validity was confirmed by using confirmatory factor analysis. The data were analyzed using correlation analysis and path analysis to test the effect of CQ on crosscultural adjustment, and the moderating effect of EI on the relationship between CQ and cross-cultural adjustment. The results showed that CQ had a positive effect on crosscultural adjustment. In addition, we found that CQ had a positive effect on EI. The findings of the research showed that emotional intelligence in not significantly the mediator variable. Emotional intelligence has a positive and significant effect on cross-cultural adjustment. The findings of this study contribute to the body of knowledge in the field of CQ and crosscultural research, and it provides practical implications for individuals seeking to improve their cross-cultural effectiveness, enhancing their cultural intelligence and emotional intelligence, specifically in tourism industry.
\end{abstract}

\section{Introduction}

Tourism is one of the world's biggest service industries, one of the most significant traits of which is face-to-face communication. Those working in various parts of this industry such as hotels, travel agencies, restaurants, theme parks, etc., are in direct communication with customers from various parts of the world facing different cultures. What makes the industry more complicated is the cultural context in which the interactions between service providers and customers occur. Those involved in the tourism industry face various cultures on a daily basis and thus should match themselves to various circumstances. Statistics indicate that cultural misunderstanding less influences the people who are aware of cultural issues (Lin et al., 2012). Knowing about cultural differences plays an importance role for tour leaders who are in constant contact with foreign tourists.

\footnotetext{
*Corresponding author. Tel: +989356211316

E-mail addresses: arghavan hadinejad@yahoo.com (A. Hadinejad) 
In terms of the increasing diversity of the workforce in today's world, sociopolitical and economic cross-cultural interactions happen, frequently. These interactions occur under various working circumstances, such as short and long-term business travels to foreign countries and going abroad for other purposes such as studying (Black et al., 1990). People may encounter different types of hardships and challenges in a cross-cultural context because of transition from familiar to unfamiliar settings. For instance, in an unfamiliar environment, people experience challenges with regard to adjusting to a new culture, interaction and communication with the host community, language use, religion, politics, etc., frequently. Because of these obstacles, different intercultural misunderstandings and conflicts appear, specifically because of the lack of cultural and emotional understanding of differences (Lin et al., 2012).

One of the important factors arising to understand more about tolerance in multicultural environments is cultural intelligence. In order to fill the gap of cultural differences and dispense with the resultant feeling of insecurity and unease on both sides, it is necessary to recognize these differences and improves the ability to communicate with foreigners. In other words, those who adapt themselves to various situations more easily have no major problem in embracing cultural differences. Cultural intelligence can serve as an index to evaluate the ability of adaptation with the new cultural structure. Earley (2002) introduced the concept of cultural intelligence to address the effect of individual differences on the formation of intercultural communications. The more one is culturally intelligent, the more he/she is able to understand various cultures and adapt him/herself to different cultural contexts (Earley \& Ang, 2003).

Not everyone is able to use cultural intelligence to adapt him/herself to intercultural environments. When the environment changes, people may face cultural challenges and find out that the behavioral patterns, emotions, attitudes and cultural values accepted in their own cultural context, may not be acceptable in other environments (Black \& Gregersen, 1991). When in different cultural environments, people adapt themselves to the new situation and this is possible through cross-cultural adjustment.

Cross-cultural adjustment is usually defined as the degree of one's psychological comfort with various characteristics of the host culture (Black, 1988; Nicholson, 1984). Cross-cultural adjustment needs to address not only the work environments, but also weather conditions, local foods, linguistic diversity, cultural differences, and communication with the host society. This adjustment needs both short and long-term processes. If cross-cultural adjustment is carried out, effectively, it will result in psychological health, satisfaction, a good relationship with the host society and harmony with the working environment (Harrison et al., 2005).

Today, psychologists consider emotional intelligence as an important characteristic difference along with scientific intelligence and contend that these differences can directly influence people's ability of communication and thus their whole lives. Emotional intelligence is the people's ability to express their individual emotions and to understand other people's emotions (Law et al., 2004). Mayer and Salovey (1995) argued that people with a high level of emotional intelligence were more in control of their emotions in various situations and are more flexible than individuals with low emotional intelligence. Improving one's cultural and emotional intelligences will help one adapt him/her to the work place, the host society and other general situations.

Recent research contends that people with a high level of CQ in their native culture would not necessarily capable of successfully adapting themselves to other cultural settings. Nevertheless, they might have a better chance of adjusting to other cultural environments, successfully (Moon, 2010). Other studies indicate that cultural intelligence was one way or another related to emotional intelligence since people with a high level of emotional intelligence are mostly emotionally welladjusted (Earley et al., 2006). 
With the increasing interest of politicians in non-oil revenue, tourism industry has received much more attention in the recent years. Considering the industry's great potential to increase income, employment and foreign exchange earnings, and due to the little economic leakage, many of the policy makers try to replace the oil income with what the lucrative tourism industry can offer. This project aims to study the concept of cultural intelligence and to analyze the relationship between cultural intelligence and cross-cultural adjustment considering the mediator agent of emotional intelligence among outgoing tour leaders of city of Tehran, Iran. This research project aims to offer solutions and clues to tour leaders in general and outgoing tour leaders of Tehran in particular so that they would successfully control the challenges of cultural differences and manage their intercultural communication.

The results of this research project can help improve the relationship between tour leaders and tourists and this in itself can increase tourists' satisfaction, which is an efficient and valuable word of mouth advertisement for our country and thus facilitates the entrance of foreign tourists.

\section{Theoretical background and hypotheses}

\subsection{Cultural Intelligence}

Earley and Ang (2003) are believed to be the first who introduced the concept of cultural intelligence. They defined cultural intelligence (CQ) as the ability to learn new patterns in cultural interactions and provide correct behavioral responses to these patterns. Cultural intelligence is, in fact, the ability to produce interactive and effective reactions to those people who are from various cultural backgrounds. Cultural intelligence enables people to recognize cultural differences through knowledge and understanding and behave appropriately in the face of different cultures (Van Dyne \& Ang, 2005).

Cultural intelligence has four perspectives, which will be elaborated in the following sections: the meta-cognitive aspect, which deals with the way an individual understands intercultural experiences. First of all, this aspect includes devising strategies before the intercultural encounter, analyzing the assumptions during the encounter and modifying mental maps in the case real experiences turn out to be different from the past expectations (Naeiji \& Abbasalizadeh, 2011). Individuals with a high level of meta-cognitive cultural intelligence possess mental processes that allow them to know the time and the way of applying their cultural knowledge (Ang et al., 2007).

Secondly, the cognitive aspect, which addresses the people's understanding of cultural similarities and differences and demonstrates the people mental and cognitive maps and their understanding of other cultures. The cognitive perspective of cultural intelligence includes the understanding of economic and legal systems, dominant norms in social interactions, religious beliefs, aesthetic values and the languages of other cultures. Cognitive cultural intelligence helps understand cultural similarities in order to employ them to establish communication (Naeiji \& Abbasalizadeh, 2011). People with a high level of cognitive cultural intelligence can interact more effectively with those from various cultures (Ang et al., 2007).

The motivational aspect is the third factor, which concerns an individual's interest in experiencing other cultures and communication with the people of other cultures. This motivation includes one's interest in multicultural interactions and the self-confidence, which allows one to behave effectively in various cultural situations. With regard to this aspect of cultural intelligence, people can establish effective cultural interactions only if they are highly motivated and self-confident and believe in their abilities (Naeiji \& Abbasalizadeh, 2011). Someone with a high level of motivational cultural intelligence are inclined to face the challenges happening in the new cultural environment and thus to defeat frustration, which influences the ability to adapt to an unfamiliar culture (Ang et al., 2007). Finally, the behavioral aspect is the last item, which shows an individual's ability to employ appropriate verbal and non-verbal behaviors towards various cultures. The behavioral cultural 
intelligence includes a variety of flexible behavioral responses used under various circumstances and are modified and revised considering each specific interaction or situation (Naeiji \& Abbasalizadeh, 2011). Appropriate communicational abilities manifested in words, tone of speech, body language, facial expressions, and gestures, can help people be more easily accepted by in a given culture and develop better social relationships (Ang et al., 2007).

\subsection{Cross-cultural Adjustment}

Cross-cultural adjustment is considered a psychological outcome associated with adaptation, which signifies the degree of comfort one feels "in his or her new role and the degree to which he or she feels adjusted to the role requirements" (Black, 1988). Black's (1988) model is a popular technique and serves as the basis for many previous research projects about crosscultural adjustment (Palthe, 2004). Black's model has three dimensions including general adjustment, interaction adjustment, and work adjustment.

General adjustment influences on the everyday lives of migrants and it is referred to people's comfort with the general living conditions (Reegard, 2011). These elements include living conditions, housing, food, shopping, living costs, recreational facilities, and health care (Harrison \& Voelker, 2008). Interaction adjustment includes the calm and peace, which people experience while interacting with the host societies in working or other environments. Reaching this level is the most difficult part of adaptation since various cultures have different traditions, cultural norms, behaviors and expectations (Black et al., 1991). This aspect also includes socializing and forming everyday relationships with the host society (Harrison \& Voelker, 2008). Work adjustment, which addresses job responsibilities, performance standards and regulatory responsibilities, is realized when people adapt themselves to their work roles, responsibilities, and environments (Reegard, 2011).

\subsection{Emotional Intelligence}

Salovey and Mayer (1990) first introduced emotional intelligence and defined emotional intelligence as a kind of social intelligence, which enables an individual to observe others' actions, differentiates between different emotions and channels one's thoughts and actions using this information (Salovey \& Mayer, 1990). Many researchers describe EI in terms of four factors including Self-Emotions Appraisal (SEA), which addresses an individual's ability to figure out his or her profound emotions and to express those emotions naturally. Others-Emotions Appraisal (OEA), that is, the individual's ability to perceive and understand other people's emotions. Regulation of Emotion(ROE), which refers to the individual's ability to supervise and evaluate his/ her own emotions and perform quick adjustments and modifications. Finally, Use of Emotion (UOE) is the last one, which means the individual's ability to channel his/her emotions in a positive and productive way to carry out positive, constructive activities and personal performance (Lin et al., 2012).

\subsection{Cultural Intelligence and Cross-cultural Adjustment}

The research projects in this field have mostly focused on the different aspects of cultural intelligence. Few research projects have addressed the relationship between cultural intelligence and factors such as adjustment in working or other environments on an international scale.

Cultural intelligence is associated with the individual's ability to effectively adapt him/herself to the new cultural structure. That's why the people with a high level of cultural intelligence are expected to succeed in their international missions in new cultural environments. It is usually believed that all aspects of cultural intelligence are associated with cross-cultural adjustment (Ramalu et al., 2011). The research projects in this field stress the effect of the four aspects of cultural intelligence on various variables. For example, some research indicates that there was a positive relationship between the cognitive aspect of cultural intelligence and cross-cultural adjustment, because it presents the 
factor of knowledge in the process of adaptation; that is, it indicates the knowledge of public culture and the knowledge of cultural differences (Ang et al., 2006). According to Wiseman et al. (1989), cultural knowledge is of great significance in communication with the people of other cultures since it decreases the risk of misunderstanding. In a similar manner, the people with a high level of cognitive cultural intelligence adapt themselves to new cultural environments more quickly and more easily because they can recognize the unique and specific aspects of other cultures.

Ang et al. (2007) contended that motivational cultural intelligence and behavioral cultural intelligence were associated with cultural adjustment, successfully. Lee and Sukoco (2007) reported that three dimensions of cultural intelligence, cognition, motivation, and behavior maintained an important effect on one's general living conditions, working environment and communication with native people. There is a positive relationship between motivational cultural intelligence and cross-cultural adjustment because people with a high level of cognitive cultural intelligence could deeply be interested in other cultures and thus can succeed in various cultural situations (Templer et al., 2006).

Ang et al. (2004) contend that motivational cultural intelligence was not only associated with gender, age and citizenship, but also to the general adjustment. They also reported a positive relationship between behavioral cultural intelligence and cross-cultural adjustment, since people with a high level of behavioral cultural intelligence were more flexible and thus could change their behaviors in response to environmental sings, and particularly cultural signs (Gudykunst et al., 1988). Accordingly, this study proposes the following hypothesis:

Hypothesis 1: There is a significant relationship between outgoing tour leaders' cultural intelligence and cross-cultural adjustment.

\subsection{Cultural intelligence and emotional intelligence}

Few research projects have studied the relationship between cultural intelligence and emotional intelligence. Theoretically, an individual's EI level is probably associated with their mental intelligence (e.g. Cognitive CQ) in various cultures and environments. In fact, humans are different in various manifestations of intelligence such as IQ, CQ, and EI. It is not common to trace a person possessing a high level of intelligence in all these dimensions (Gardner, 1993; Sternberg, 1985).

Moon (2010) examined the relationship between the four aspects of cultural intelligence and aspects of emotional intelligence. The study proved the difference and validity of cultural intelligence in comparison with emotional intelligence, which were consistent with other studies. The analysis of the results indicated that those who possess social abilities such as social awareness and communication management had a higher level of cultural intelligence than people with individual talents and abilities. In the end, the results confirmed the relationship between specific characteristics of emotional intelligence and specific aspects of cultural intelligence.

According to Earley et al. (2006), cultural intelligence is in one way or another associated with emotional intelligence since individuals with a high level of cultural intelligence are more or less well-adjusted emotionally. In a similar manner, while interacting with various people from different cultures or while facing cultural problems within professional and non-professional spheres, people with a higher level of emotional intelligence are able to process cultural cues more easily. They also express their emotions effectively, understand other people's intentions more accurately in order to interpret cultural meanings, control personal emotions to avoid misunderstanding and miscommunication. Finally, they employ the right emotion to express themselves verbally and non-verbally. This helps to explain the great importance of CQ and EI. Therefore, people with a high level of Cultural Intelligence in their native culture may not 
necessarily be successfully adapt to different unfamiliar cultural settings; however, they may have a better chance (Moon, 2010). Therefore, the following hypothesis is proposed:

Hypothesis 2: There is a significant relationship between outgoing tour leaders' cultural intelligence and emotional intelligence.

\subsection{Emotional intelligence as a moderator agent between cultural intelligence and cross-cultural adjustment}

In recent years, many researchers have concentrated on EI. According to Bar-On (2000), for instance, the competencies to solve adjustment obstacles in a cultural context and therefore to obtain a better cultural fit is viewed as Jassawalla et al. (2004). Gabel et al. (2005) showed in their studies that EI could be effective in expatriating manager selection, absolutely. It can also reduce the hesitation and frustration, which originate from cross-cultural adaptation and augment success in international assignments. Kim et al. (2006) maintained that through getting along with local individuals, emotional and informational support could contribute to the reduction of uncertainty in individuals and in an easier fashion obtain information concerning cultural norms and behaviors.

Earley and Peterson (2004) and Earley and Ang (2003) stated that adaptation across cultures is not included in EI and it may be culturally specific. In other words, those individuals whose EI is high in their own native culture may not be capable of generalizing this ability across cultural contexts. Moreover, effective intercultural adaptation and interaction cannot be achieved through automatic transferring of these skills. Earley and Peterson (2004), however, highlighted that a sufficient discussion of the cross-cultural context.

Moon (2010) reported that EI could be effective when having contacts with people coming from various cultural backgrounds. Gabel et al. (2005) showed that cultural differences act as moderators and exert important influences upon the intensity of the relationship between EI and cross-cultural adjustment. In other words, the cultural gap between the host and home cultures of global managers could be filled with EI, which leads to increasing the possibilities for better cross-cultural adjustment. Gabel et al. (2005) reached to a higher relationship between EI and cultural adjustment which they found significant; all dimensions of EI. Excluding this last case, most of the literature reviews reported that EI and its dimensions could play essential role as a predictor of cross-cultural adjustment.

Yoo et al. (2006), for instance, showed in their study of international students that emotional recognition ability, as a component of EI, can foresee positive intercultural adjustment. Emotional recognition is essential for positive cross-cultural adjustment. These emotions are unavoidable in intercultural life. According to Lillis and Tian (2009), through its dimensions of empathy and social skills in a cultural environment, EI could raise sensitivity and awareness of cultural differences and minimize cross-cultural miscommunication within dissimilar groups. Lin et al. (2012) demonstrated that cultural intelligence had a positive impact on cross-cultural adjustment and emotional intelligence modifies the relationship between cultural intelligence and cross-cultural adjustment in a positive way.

All in all, it can be logically assumed that EI with its dimensions could help individuals give word to their emotions in a suitable way and watch their own behaviors well, in order to prevent misunderstandings and conflicts happening in a cross-cultural context. Therefore, EI with its dimensions are essential factors, which make adjustment easier when encountering a totally different cultural environment. Accordingly, this study proposes the following hypotheses.

Hypothesis 3: There is a significant relationship between cultural intelligence and cross-cultural adjustment considering the mediator agent of emotional intelligence among outgoing tour leaders.

Hypothesis 4: There is a significant relationship between outgoing tour leaders' emotional intelligence and cross-cultural adjustment. 
With regard to the above-mentioned facts, the conceptual model of the research project is designed in Fig. 1 as follows,

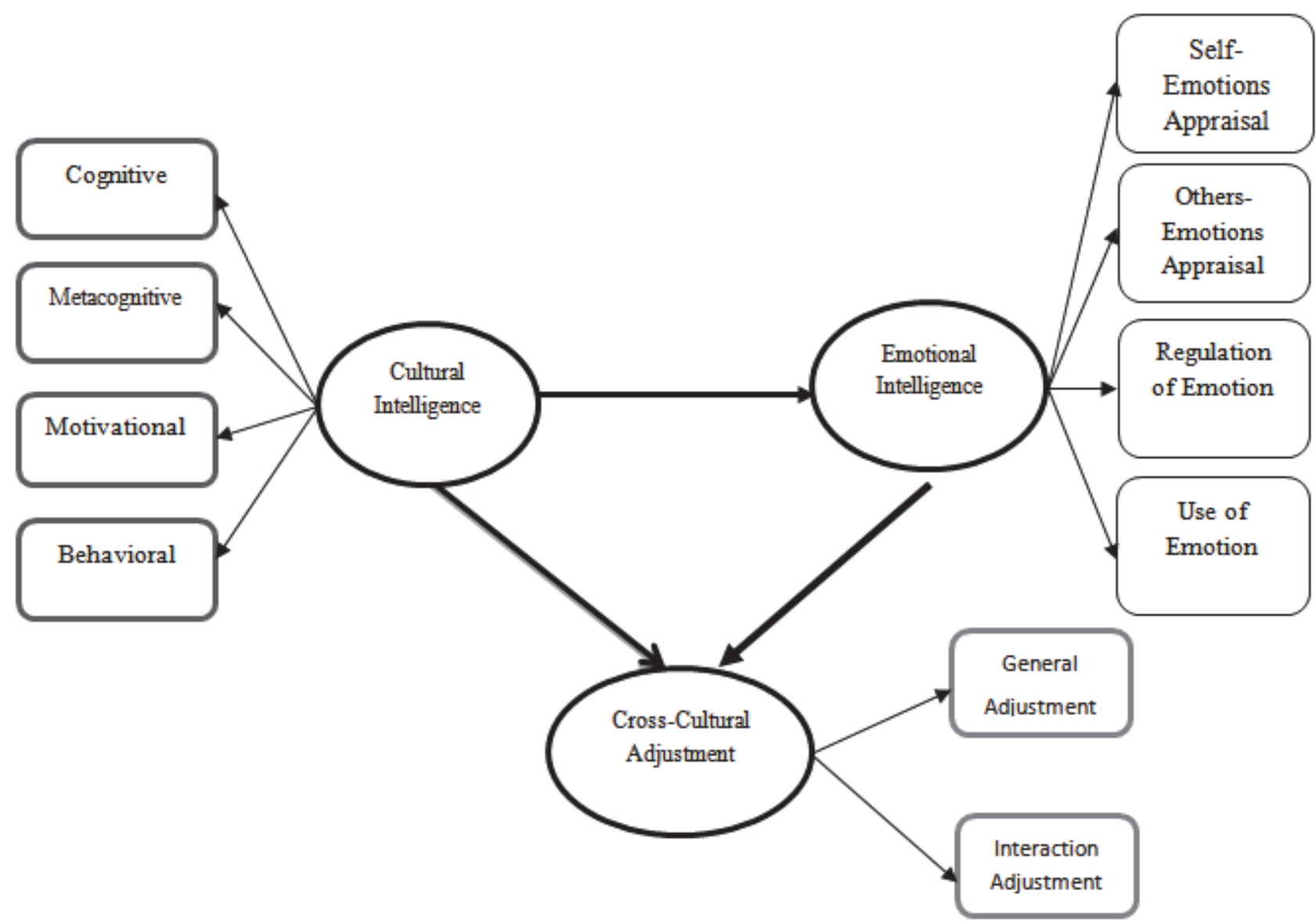

Fig. 1. The proposed study

\section{Method}

\subsection{Sample and data collection}

This research is an applied one based on the aim of the study and is descriptive from the respect of gathering data. The data were analyzed using correlation analysis and path analysis to test the effect of CQ on cross-cultural adjustment, and the moderating effect of EI on the relationship between CQ and cross-cultural adjustment. The statistical society of this research includes leaders of outgoing tours from Tehran. For determining sample size, sampling formula from infinite society was used. Since a number of questionnaires might have not been filled and returned or not fully answered, 400 questionnaires were distributed among which 330 questionnaires were confirmed. Content validity of questionnaire was achieved with the help of thesis supervisor and reader, and its construct validity was achieved through confirmatory factor analysis. The normality of data was achieved with the help of Kolmogorov-Smirnov test to investigate a significant relation between main variables of Pearson correlation test and eventually investigate first, second, third, and fourth hypotheses through modeling structural equation and Pearson correlation coefficient.

\subsection{Measures and Variables}

Adopting CQ scale from Ang et al. (2007), 20 CQ items were classified into four dimensions. A nineitem measure from Robie and Ryan (1996) was used to measure cross-cultural adjustment. From this 
measure the items related to work were excluded. In addition, a sixteen-item measure by Law and Wong (2002) was used to evaluate the level of EI among respondents. Questionnaire reliability was examined with the help of Cronbach alpha test. Cronbach alpha was 0.81 in cultural intelligence, 0.79 in cross-cultural adjustment, 0.88 in emotional intelligence, and 0.86 for the alpha of the research. Since they were all above 0.60 , they were accepted which indicates accepted reliability of research questionnaire.

\section{Results}

To test the normality of data distribution, Kolmogorov-Smirnov test was used. The level of significance for cultural intelligence variable is 0.329 which is bigger than 0.05 and therefore this variable is normal. To determine the variable concerning cross-cultural adjustment the level of significance in cross-cultural variable is 0.075 which is bigger than 0.05 and therefore this variable is normal too. Since variables data were distributed normally, parametric tests were used and Pearson correlation test was used to investigate the relation between main variables. Moreover, structural equation modeling was used to test hypotheses and study the causal relation between variables.

The means of research main variables are in an appropriate level (almost bigger than average). Also as Table indicates there is a positive and significant relation between cultural intelligence and crosscultural adjustment $(\mathrm{Sig}<0.01, \mathrm{r}=0.61)$, cultural intelligence and emotional intelligence $(\mathrm{Sig}<0.01$, $\mathrm{r}=0.40$ ), and emotional intelligence and cross-cultural adjustment $(\mathrm{Sig}<0.01, \mathrm{r}=0.62)$. Since relations were significant in the certainty level of $99 \%$, all relations between variables were significant and hypotheses investigating the relation of two variables were confirmed. As Table indicates, since correlation coefficient determines the intensity of significance between two variables, it can be said that the relation between emotional intelligence and cross-cultural adjustment with 0.62 correlation is in a higher level than the relation between cultural intelligence and emotional intelligence and it is almost in the same level with the relation between cultural intelligence and cross-cultural adjustment.

Table 1

Main variables`s Pearson Correlation

\begin{tabular}{|c|c|c|c|c|c|}
\hline Variable & Mean & Std. Deviation & 1 & 2 & 3 \\
\hline 1.Cultural Intelligence & 3.98 & 0.43 & 1 & & \\
\hline 2.Cross-cultural Adjustment & 4.02 & 0.49 & $0.61^{* *}$ & 1 & \\
\hline 3.Emotional Intelligence & 3.90 & 0.53 & $0.40^{* *}$ & $0.62^{* *}$ & 1 \\
\hline
\end{tabular}

* Correlation is significant at the 0.05 level ** Correlation is significant at the 0.01 level

\subsection{Confirmatory Factor Analysis (CFA)}

In this part, data gathered from questionnaires are studied using LISREL software.

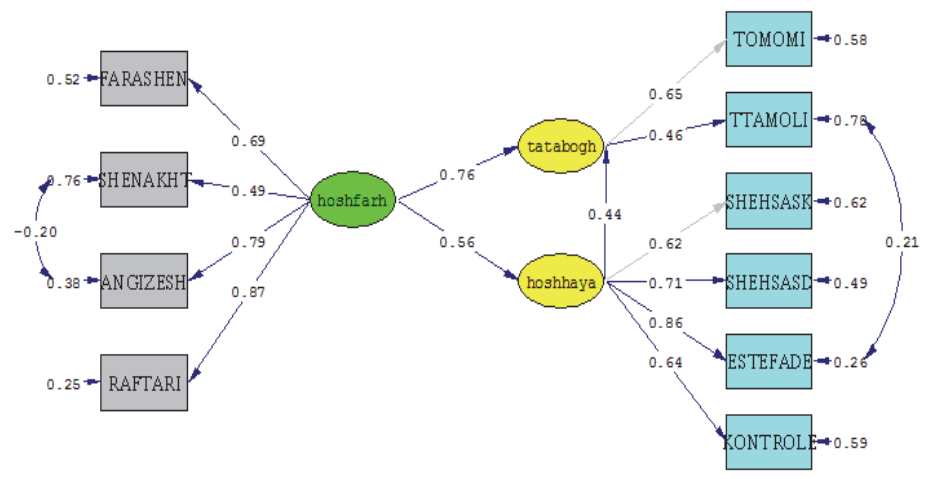

Chi-Square $=87.46, \mathrm{df}=30, \mathrm{P}-\mathrm{value}=0.00000, \mathrm{RMSEA}=0.087$

Fig. 3. The results of structural equation modeling 
Table below reveals the most important of indexes and shows that the pattern is in an acceptable status in the explanation and fit.

Table 2

Fitting Indices

\begin{tabular}{lll}
\hline Index Name & Obtained Value & Acceptable Range \\
\hline$\chi^{2} / \mathbf{d f}$ & 2.91 & Less than 3 \\
GFI & 0.91 & More than 0.9 \\
RMSEA & 0.087 & Less than 0.9 \\
CFI & 0.93 & More than 0.9 \\
AGFI & 0.86 & More than 0.9 \\
NFI & 0.95 & More than 0.9 \\
NNFI & 0.89 & More than 0.9 \\
\hline
\end{tabular}

According to the results of Table 2, all fit indexes for the model are within an acceptable level. Therefore, it can be said that the suggested conceptual model has an acceptable fit.

\subsection{Hypothesis Testing}

The first hypothesis states that there was a significant relationship between cultural intelligence and cross-cultural adjustment. According to $t$ statistical figure, cultural intelligence variable in the certainty level of $99 \%$ has a positive and significant effect on tour leaders' cross-cultural adjustment. The relation between these two variables is a linear and direct one. Therefore, when cultural intelligence improves, tour leaders' cross-cultural adjustment increases. $\mathrm{R}^{2}$ equals 0.37 . Thus, cultural intelligence variable could predict $37 \%$ of changes of tour leaders' cross-cultural adjustment.

According to the second hypothesis, tour leaders' cultural intelligence has a significant relation with their emotional intelligence. According to $t$ statistical figure, cultural intelligence variable in the certainty level of $99 \%$ has a positive and significant effect on emotional intelligence. The relation between these two variables is a linear and direct one. Therefore, when tour leaders' cultural intelligence improves and changes, their emotional intelligence increases. $\mathrm{R}^{2}$ equals 0.31 . Thus, cultural intelligence variable could predict $31 \%$ of changes of tour leaders' emotional intelligence.

The third hypothesis indicates that cultural intelligence, given the mediatory role of emotional intelligence, has a significant relation with tour leaders' cross-cultural adjustment. In this hypothesis, the simultaneous investigation of two paths in which cultural intelligence effects cross-cultural adjustment is required. This is done in line with the method proposed by Venkatraman (1989) to investigate the significance of role of variables' mediators. In this regard, whenever the amount achieved by multiplying correlations of paths qualified for mediatory variable is bigger than the direct relation of dependent and independent variables, it can be said that the role of mediatory variables is significant. This effect is calculated as the following:

Indirect effect $=$ direct effect of cultural intelligence on $\mathrm{EQ} \times$ direct effect of emotional intelligence on cross-cultural adjustment

The multiplied result of correlations of paths qualified for mediatory variable is 0.24 which is smaller than the direct relation of model's direct and indirect variables which equals 0.76 . Thus, it can be inferred that emotional intelligence significantly plays the role of mediator in this relation and as a result the second hypothesis of research is not confirmed. Total $\mathrm{R}^{2}$ equals 0.21 given the direct path. This coefficient investigates the predicting ability of dependent variable by independent variable(s). Therefore, considering mediatory variable EQ, cultural intelligence has predicted $21 \%$ of changes of cross-cultural adjustment. 
According to the fourth hypothesis, tour leaders' EQ has a significant relation with their cross-cultural adjustment. According to t statistical figure, EQ variable in the certainty level of $99 \%$ has a positive and significant effect on cross-cultural adjustment. The relation between these two variables is a linear and direct one. Therefore, when tour leaders' EQ improves and changes, their cross-cultural adjustment increases. $\mathrm{R}^{2}$ equals 0.27 . Thus, EQ variable could predict $27 \%$ of changes of tour leaders' cross-cultural adjustment. Table below shows a summary of hypotheses results.

Table 3

The results of path analysis

\begin{tabular}{|c|c|c|c|c|}
\hline Research hypotheses & Path Coefficient & Correlation & $\mathrm{t}$ & Hypotheses Results \\
\hline 1 & 0.76 & 0.37 & $5.62^{* *}$ & Not Rejected \\
\hline 2 & 0.56 & 0.31 & $4.65^{* *}$ & Not Rejected \\
\hline 3 & 0.24 & (Considering Direct Path 0.21) & 3.03 & Not Rejected \\
\hline 4 & 0.44 & 0.27 & $3.19^{* *}$ & Not Rejected \\
\hline
\end{tabular}

\section{Discussion}

The purpose of the present study was to examine the relationships among CQ, EI, and crosscultural adjustment. The results of this research project show that cultural intelligence had a positive and significant influence on tour leaders' cross-cultural adjustment at the $99 \%$ significance level (0.76 path coefficient). Hypotheses testing showed that there was a causal relationship between cultural intelligence and cross-cultural adjustment among tour leaders by means of modeling structural equations. The results of this research project show that $37 \%$ of the fluctuations of crosscultural adjustment could be defined and described by the variable of cultural intelligence. The results of this research project confirm the findings of previous research projects carried out by Ramalu et al. (2011), Wiseman et al. (1989), Lee \& Sukoco (2007), Templer et al. (2006), Ang et al. (2006) and Gudykunst (1988) . The results demonstrate that the outgoing tour leaders with a high level of cultural intelligence could adjust themselves to the situations of their travel destination, embrace the general living conditions of the host country and establish a positive relationship with the people.

Results show that the outgoing tour leaders' cultural intelligence has a positive and significant effect on their emotional intelligence at the $99 \%$ significance level (0.56 path coefficient). Hypotheses testing showed that there is a causal relationship between cultural intelligence and emotional intelligence among tour leaders by means of modeling structural equations. The results of this research project show that $31 \%$ of the fluctuations of tour leaders' emotional intelligence can be defined and described by the variable of cultural intelligence. Those who have a better understanding of their environment can establish a positive communication with it and can control and leader the environmental variables more effectively. This is manifested in cultural intelligence and its relationship with emotional intelligence, which mostly focuses on people's emotions. These results are in line with the findings of Moon's (2010) research. The results do not confirm a causal relationship between cultural intelligence and cross-cultural adjustment considering the tour leaders' emotional intelligence since path coefficient value considering mediator variable, is less than direct path coefficient between independent variable and dependent variable. The results of this research show that $21 \%$ of the fluctuations of cross-cultural adjustment can be defined and described by the variables of cultural intelligence and emotional intelligence. The third hypothesis is not confirmed, but the influence of cultural intelligence through emotional intelligence is undeniable; however, in comparison with the influence of emotional intelligence, this is not directly significant. As previously discussed, those with a higher level of cultural intelligence have a stronger emotional intelligence, and thus are more flexible in the reception of environmental variables especially human behaviors. Lin et al. (2012) studied the influence of cultural intelligence and emotional intelligence on crosscultural adjustment. Their findings show that cultural intelligence, which controls factors such as age, gender, and English language mastery, has a positive influence on cross-cultural adjustment, and 
emotional intelligence modifies the relationship between cultural intelligence and cross-cultural adjustments in a positive way.

The findings of this study also show that the outgoing tour leaders' emotional intelligence has a positive and significant effect on their cross-cultural adjustment at the $99 \%$ significance level $(0.44$ path coefficient). Hypotheses testing also showed that there is a causal relationship between emotional intelligence and cross-cultural adjustment among tour leaders by means of modeling structural equations. The results of this research show that $27 \%$ of the fluctuations of tour leaders' cross-cultural adjustment can be merely defined and described by the variable of emotional intelligence. As previously discussed, emotional intelligence enables people to monitor their own emotional states and also others' actions, to distinguish between different emotional states and employ their knowledge and information in order to channel their thoughts and actions (Salovey \& Meyer, 1990). All these elements provide a man with the power to recognize, choose and behave effectively and optimally. Such a person can adapt himself to the cultural environment and thus develop a better understanding of it. This characteristic is especially required for tour leaders who should interact with different people from different cultures and thus should employ different behaviors while communicating with each cultural group. Jassawalla et al. (2004), Gabel et al. (2005) and Kim et al. (2006) also achieved similar findings.

\section{References}

Ang, S., Van Dyne, L., Koh, C., \& Ng, K. (2004). The measurement of cultural intelligence. New Orleans, LA.: Paper presentation at the 2004 annual meeting of the academy of management.

Ang, S., Van Dyne, L., \& Koh, C. (2006). Personality correlates of the four-factor model of cultural intelligence. Group and Organization Management, 31, 100-123.

Ang, S., Van Dyne, L., Koh, C., Ng, K. Y., Templer, K. J., Tay, C., \& Chandrasekar, N. A. (2007). Cultural intelligence: Its measurement and effects on cultural judgment and decision making, cultural adaptation and task performance. Management and Organization Review, 3(3), 335-371.

Bar-On, R. (2000). Emotional and social intelligence: Insights from the emotional quotient inventory. The handbook of emotional intelligence. San Francisco, CA: Josey-Bass.

Bhaskar-Shrinivas, P., Harrison, D. A., Shaffer, M. A., \& Luk, D. M. (2005). Input-based and time-based models of international adjustment: Meta-analytic evidence and theoretical extensions. Academy of Management Journal, 48(2), 257-281.

Black, J. S. (1988). Work role transitions: A study of American expatriate managers in Japan. Journal of International Business Studies, 19(2), 277-294.

Black, J. S., \& Gregersen, H. B. (1991). When Yankee comes home: Factors related to expatriate and spouse repatriation adjustment. Journal of International Business Studies, 22(4), 671-694.

Black, J. S., \& Mendenhall, M. (1990). The U-curve adjustment hypothesis revisited: A review and theoretical framework. Journal of International Business Studies, 22(2), 225-247.

Black, J. S., Mendenhall, M., \& Oddou, G. (1991). Toward a comprehensive model of international adjustment: An integration of multiple theoretical perspectives. Academy of management review, 16(2), 291-317.

Earley, P. C. (2002). Defining interactions across cultures and organizations: Moving forward with cultural intelligence. Research in Organizational Behavior, 24, 271-299.

Earley, P. C., \& Ang, S. (2003). Cultural intelligence: Individual interactions across cultures. Stanford: Stanford University Press.

Earley, P.C., Ang, S.., \& Tan, J.-S. (2006). CQ: Developing cultural intelligence at work. Stanford, CA: Stanford Business Books.

Earley, P. C., \& Peterson, R. S. (2004). The elusive cultural chameleon: Cultural intelligence as a new approach to intercultural training for the global manager. Academy of Management Learning and Education, 3, 100-115.

Gabel, R. S., Dolan, S. L., \& Cerdin, J. L. (2005). Emotional intelligence as predictor of cultural adjustment for success in global assignments. Career Development International, 10(5), 375-395.

Gardner, H. (1993). Multiple intelligences: The theory in practice. New York: Basic Books. 
Gudykunst, W., Ting-Toomey, S., \& Chua, E. (1988). Culture and Interpersonal Communication. Newbury Park, California: Sage.

Harrison, J. K., \& Voelker, E. (2008). Two Personality Variables and the Cross-Cultural Adjustment of Study Abroad Students. Frontiers: The Interdisciplinary journal of study abroad, 17, 69-87.

Jassawalla, A., Truglia, C., \& Garvey, J. (2004). Cross-cultural conflict and expatriate manager adjustment: An exploratory study. Management Decision,42(7), 837-849.

Kim, K., Kirkman, B. L., \& Chen, G. (2006). Cultural intelligence and international assignment effectiveness: A conceptual model and preliminary findings. Paper presentation at the 2006 annual meeting of the academy of management. Atlanta, GA

Law, K. S., Wong, C. S., \& Song, L. J. (2004). The construct and criterion validity of emotional intelligence and its potential utility for management students. Journal of Applied Psychology, 89(3), 483-496.

Lee, L., \& Sukoco, B. (2007). The effects of expatriate personality and cultural intelligence on expatriate adjustment: The moderating role of expatriate. Melbourne, Australia: Paper presentation at the 13th Asia Pacifica management conference.

Lillis, M. P., \& Tian, R. G. (2009). Cross-cultural communication and emotional intelligence: Inferences from case studies of gender diverse groups. Marketing Intelligence \& Planning, 27(3), 428-438.

Lin, Y. C., Chen, A. S. Y., \& Song, Y. C. (2012). Does your intelligence help to survive in a foreign jungle? The effects of cultural intelligence and emotional intelligence on cross-cultural adjustment. International Journal of Intercultural Relations, 36(4), 541-552.

Mayer, J. D., \& Salovey, P. (1995). Emotional intelligence and the construction and regulation of feelings. Applied and preventive psychology, 4(3), 197-208.

Moon, T. (2010). Emotional intelligence correlates of the four-factor model of cultural intelligence. Journal of Managerial Psychology, 25(8), 876-898.

Mount, C., \& Downton, C. (2006). Alzheimer disease: Progress or profit?. Nature Medicine, 12(7), 780-784.

Naeiji, M., \& Abbasalizadeh, M. (2011). Cultural Intelligence and its relationship with private organization managers' entrepreneurial characteristic in Iran. Tose'e Karafarini. 27-44 [In Persian].

Nicholson, N. (1984). A theory of work role transitions. Administrative Science Quarterly, 29, 172-191.

Palthe, J. (2004). The relative importance of antecedents to cross-cultural adjustment: Implications for managing a global workforce. International Journal of Intercultural Relations, 28, 37-59

Ramalu, S., Wei, C., \& Rose, R. (2011). The effects of cultural intelligence on cross-cultural adjustment and job performance amongst expatriates in Malaysia. International Journal of Business and Social Science, 59-71.

Reegard, K. (2011). Facilitating cross-cultural adjustment: The case of north European expatriates in china.

Robie, C., \& Ryan, A. M. (1996). Structural equivalence of a measure of cross-cultural adjustment. Educational and Psychological Measurement, 56(3), 514-521.

Salovey, P., \& Mayer, J. (1990). Emotional intelligence. Imagination, Cognition, and Personality, 9, 185211.

Sternberg, R. J. (1985). Beyond IQ: A triarchic theory of human intelligence. New York, NY: Cambridge University Press.

Templer, K. J., Tay, C., \& Chandrasekar, N. A. (2006). Motivational cultural intelligence, realistic job preview, realistic living conditions preview, and cross-cultural adjustment. Group \& Organization Management, 31(1), 154-173.

Van Dyne, L., \& Ang, S. (2005). Cultural intelligence: An essential capability for individual in contemporary organizations. Singapore: Michigan State University and Nanyang Technological University.

Wiseman, R. L., Hammer, M. R., \& Nishida, H. (1989). Predictors of intercultural communication competence. International Journal of Intercultural Relations, 13(3), 349-370.

Yoo, S. H., Matsumoto, D., \& LeRoux, J. A. (2006). The influence of emotion recognition and emotion regulation on intercultural adjustment. International Journal of Intercultural Relations, 30(3), 345-363. 